\title{
Knowledge and Attitudes About Epilepsy Surgery Among Family Doctors in Ontario
}

\author{
Nicholas Cothros, Jorge G. Burneo, David A. Steven
}

\begin{abstract}
Background: Approximately 30\% of patients with epilepsy have medically intractable seizures, and a proportion of them are candidates for surgical treatment. The efficacy and safety of epilepsy surgery have been supported by a large number of studies, yet only a small minority of such patients in Ontario receive surgery. Methods: Family physicians in Ontario were surveyed regarding demographics, referral practices and general knowledge about epilepsy surgery. Four hundred surveys were mailed to randomly selected family physicians using contact information from the College of Physicians and Surgeons of Ontario website. Results: The response rate was $50 \%$. The majority of family physicians $(81 \%)$ always refer patients with epilepsy, most often to neurologists. General knowledge of epilepsy was mixed, with $53.7 \%$ feeling that surgery should be considered in selected cases for the treatment of epilepsy, though $53.2 \%$ did not know what type of epilepsy could be surgically treated. Conclusions: The results suggest a relatively low level of knowledge among family physicians in terms of when surgery ought to be considered, the types of epilepsy that are amenable to surgical treatment and the risks and benefits of epilepsy surgery. A lack of knowledge in these areas may partly underlie the low referral rates of epilepsy patients, though the results show that the majority of family physicians refer their patients with epilepsy to neurologists. Other factors must be considered, such as access to neurologists, epileptologists and surgical resources. Education campaigns directed at family physicians may improve knowledge and change referral practices. Future studies need to examine these possibilities.
\end{abstract}

RÉSUMÉ: Connaissances et attitudes des médecins de famille ontariens en ce qui regarde le traitement chirurgical de l'épilepsie. Contexte: Environ $30 \%$ des patients épileptiques sont atteints de crises réfractaires. Une partie d'entre eux peuvent alors être candidats à un traitement chirurgical. L'efficacité du traitement chirurgical de l'épilepsie ainsi que son absence de risques ont été prouvées par un grand nombre d'études. Pourtant, seule une petite minorité de patients ontariens en ont bénéficié. Méthodes: Nous avons effectué un sondage auprès de médecins de famille ontariens concernant les caractéristiques démographiques de leurs patients, leurs pratiques d'aiguillage et leurs connaissances générales du traitement chirurgical de l'épilepsie. Quatre cents sondages ont été postés à des médecins de familles choisis au hasard dans le site Internet de l'Ordre des médecins et chirurgiens de l'Ontario. Résultats: Le taux de participation du sondage a été de 50\%. Une majorité de médecins de famille (81\%) ont systématiquement adressé leurs patients épileptiques à des spécialistes, le plus souvent des neurologues. Les connaissances générales de l'épilepsie se sont révélées contrastées : si 53,7 \% des répondants avaient l'impression que le traitement chirurgical de l'épilepsie devait être envisagé dans des cas particuliers, 53,2\% ignoraient néanmoins les types d'épilepsie pouvant être traités au moyen de la chirurgie. Conclusions: Nos résultats suggèrent que les médecins de famille possèdent des connaissances relativement limitées des cas pour lesquels le traitement chirurgical de l'épilepsie devrait être envisagé, des types d'épilepsie qui s'y prêtent ainsi que des risques et bénéfices de ce traitement. Un tel manque de connaissances pourrait sous-tendre les faibles taux d'aiguillage de patients épileptiques, et ce, même si nos résultats montrent que la majorité des médecins de famille adressent leurs patients à des neurologues. D'autres facteurs doivent également être pris en considération, notamment l'accès à des neurologues, à des épileptologues et à des ressources du domaine de la chirurgie. Il se pourrait aussi que des campagnes de sensibilisation destinées aux médecins de famille puissent améliorer l'état des connaissances et modifier les pratiques d'aiguillage des patients. Chose certaine, des études ultérieures devront se pencher sur ces possibilités.

Keywords: Epilepsy, Epilepsy surgery, Neurology, Adult

doi:10.1017/cjn.2016.277

Can J Neurol Sci. 2016; 43: 672-677

\section{INTRODUCTION}

Approximately $30 \%$ of patients with epilepsy continue to have seizures despite medical therapy. ${ }^{1}$ Some of these patients are candidates for epilepsy surgery, the most common operation being anterior temporal lobe resection for adults with hippocampal sclerosis. ${ }^{2}$

There is ample evidence supporting the effectiveness of epilepsy surgery. Two key randomized controlled trials analyzed the efficacy of epilepsy surgery plus antiepileptic drug (AED) therapy versus AED therapy alone in the treatment of intractable mesial temporal lobe epilepsy. ${ }^{3,4}$ Both yielded evidence of superior outcomes following surgery, as opposed to AED therapy alone. Wiebe et al. ${ }^{3}$ found that, after one year, $58 \%$ of patients randomly assigned to anteromesial temporal lobe resection (ATL) were seizure-free, whereas only $8 \%$ of patients receiving AED

From the London Health Sciences Centre, Western University, London, Ontario, Canada (NC, JGB, DAS).

Received June 7, 2015. Final Revisions Submitted January 12, 2016. Date of Acceptance February 9, 2016.

Correspondence to: David A. Steven, Epilepsy Program, Department of Clinical Neurological Sciences, Western University, 339 Windermere Road, London, Ontario, Canada N6A 5A5. Email: david.steven@uwo.ca. 
therapy alone were seizure-free. Similarly, Engel et al. ${ }^{4}$ reported that none of their 23 patients receiving only AED therapy were seizurefree during a 2-year follow-up period, in sharp contrast to the 11 of 15 patients randomly assigned to undergo ATL.

The benefits of surgical treatment for refractory epilepsy extend beyond seizure control and include improved quality of life, cognition, psychosocial function and mortality, and reduced financial costs. ${ }^{5}$ The merits of epilepsy surgery are furthered bolstered by its relatively low mortality rate, ranging from 0 to $3.5 \%$ in a recent review, ${ }^{6}$ though the vast majority of reports indicate zero mortality. Across 8 retrospective cohort studies comprising 2,725 patients and a mean follow-up period ranging from 2 to 7 years, there was a total of 3 deaths $(0.1 \%)$ related to epilepsy surgery. ${ }^{7}$

Despite the strong case that can be made for epilepsy surgery as a treatment option for intractable epilepsy, it is grossly underused. In Canada, of an estimated 20,000 people with intractable epilepsy who were candidates for surgery in 1998-1999, only 352 had surgery. ${ }^{8}$ A 2006 report $^{7}$ estimated that, although there were 9,375 patients eligible for surgery, only $\sim 150$ epilepsy surgeries are performed in Ontario every per year. This discrepancy is poorly understood.

Family physicians serve as the primary portal of entry for patients into the healthcare system, including those with neurological illnesses. It stands to reason that referral practices may partly underlie the mismatching numbers of patients eligible for epilepsy surgery and those who undergo such surgery. To that end, the present study was designed to investigate the referral practices of family physicians in Ontario through a survey, with the aim of identifying any issues that may warrant future intervention.

\section{MethodS}

A survey was designed to determine general knowledge of epilepsy surgery as well as the referral patterns of family practitioners when assessing patients with epilepsy, and in particular those with medically intractable epilepsy. The survey addressed three major aspects of its respondents: demographics, referral practices and general knowledge about epilepsy surgery (Table 1). The demographic data included age range of family physicians, number of years in practice, gender and practice setting (see Table 1, survey questions 8-10). To assess referral practices, the survey investigated both when and where its respondents referred patients with epilepsy (see Table 1, survey questions 2 and 3). To assess general knowledge of epilepsy, a number of survey items posed questions relating to when surgery should be considered, the types of epilepsy that can be treated surgically, and the risks and potential benefits of epilepsy surgery (see Table 1, questions 4-7). Survey data were collected anonymously.

The study was approved by the Health Sciences Research Ethics Board at Western University. From a list of 14,191 physicians registered as a "family doctor" with the College of Physicians and Surgeons of Ontario (CPSO) in 2013, 400 were randomly selected to complete the survey. Contact information (i.e., mailing addresses) of respondents was obtained from the public CPSO website. A total of 400 surveys were initially mailed to the family physicians, along with invitation letters and \$30 gift cards (for a widely available retail bookstore) as an incentive for participation. Physicians were asked to return the survey within three weeks. Two monthly follow-up mailings were sent to the same doctors to help improve response rate. Completed surveys were either faxed or mailed to the principal investigator. Physicians agreed to voluntary participation by completing and returning the surveys. Twelve of these surveys were returned uncompleted, either because a physician had moved or did not manage patients with epilepsy. As a result, 12 additional physicians were randomly selected to complete the survey. Statistical analyses were performed using SAS software (v. 9.2, SAS Institute, Cary, NC). Data were analyzed using descriptive statistics. A Pearson $\chi^{2}$ statistic was employed for all categorical analyses. A significance level of $\alpha=0.05$ was chosen for all statistical tests, and the $p$ values in this report are two-tailed.

\section{Results}

A total of 201 of the 400 surveys were completed and returned (50\% compliance).

\section{Demographics}

The demographic data are shown in Table 2. These data demonstrate that $53 \%$ of respondents were female and that most practiced in an urban setting $(75 \%)$. The ages of the respondents ranged from 21 to $70+$ years, with the largest cohort falling between the ages of 41 and $50(30 \%)$. The respondents varied widely in terms of number of years in practice (from 0 to $>30$ years); the largest cohort (28\%) had been practicing for 21 to 30 years.

\section{Referral Practices}

Table 3 presents data regarding referral practices. Out of the 201 respondents, $87 \%$ of family physicians indicated that they managed adult patients with epilepsy in their practice. Nearly $81 \%$ of family physicians indicated that they would "always" refer patients with epilepsy, in sharp contrast to the small minority $(3.5 \%)$ who indicated that they would "never" refer patients with epilepsy. Of those family doctors who referred their patients with epilepsy, most referred their patients to general neurologists $(89.1 \%)$, while $3.5 \%$ referred their patients to an epileptologist. There was no correlation between location of practice (urban vs. rural) and the tendency of family physicians to refer their patients with epilepsy. Referral practices varied with family physicians' time in practice. Those in practice for more than 20 years were significantly less likely to refer their patients with epilepsy than those in practice for less than 20 years. Of those in practice for 20 years or less, 80/89 (89\%) "always" referred their patients with epilepsy, compared with 65/87 (75\%) of those in practice for more than 20 years $(p=0.01)$.

\section{General Knowledge of Epilepsy Surgery}

The survey data showed that general knowledge of epilepsy surgery among family doctors was mixed (see Table 4). The majority $(53.7 \%)$ felt that surgery should be considered "in selected cases" for the treatment of epilepsy, though a similarly sized majority (53.2\%) did not know what type of epilepsy could be surgically treated. Additionally, 43.8 and $45.3 \%$ of doctors were unfamiliar with the risks associated with epilepsy surgery and its potential benefits, respectively. There was no significant difference 


\section{Table 1: Survey}

\begin{tabular}{l}
\hline 1. Do you manage ADULT patients with epilepsy in your practice? (SELECT ONE) \\
\hline$\square$ Yes $\square$ No \\
\hline 2. When do you refer patients with epilepsy? (SELECT ONE) \\
\hline$\square$ Always \\
\hline$\square$ After one medication has failed \\
\hline After two or more medications have failed \\
\hline$\square$ Never (SKIP TO QUESTION 4). \\
\hline 3. Where do you MOST COMMONLY refer patients with epilepsy? \\
$\square$ General neurologist \\
$\square$ Epileptologist/epilepsy specialist \\
$\square$ Internal medicine specialist \\
$\square$ Other (Specify)
\end{tabular}

4. When do you think that surgery should be considered for the treatment of epilepsy? (SELECT ONE)

$\square$ Always

$\square$ Never

$\square$ In selected cases

$\square$ Only as a last resort

$\square$ I don't know

5. What type of epilepsy do you think can be surgically treated? (SELECT ONE)

$\square$ Generalized epilepsy

$\square$ Partial or focal epilepsy

\section{$\square$ Neither}

$\square$ Both

$\square$ I don't know

6. What is your impression of the risk of epilepsy surgery? (SELECT ONE)

$\square$ Low

$\square$ Moderate

$\square$ High

$\square$ Very High

$\square$ I don't know

7. What is your impression of the potential benefit of epilepsy surgery? (SELECT ONE)

$\square$ Low

$\square$ Moderate

$\square$ High

$\square$ Very high

$\square$ I don't know

8. Which of the following best describes the community where you practice? (SELECT ONE)

$\square \operatorname{Urban}(>100,000)$

$\square$ Rural $(<100,000)$

9. What is your gender? (SELECT ONE)

$\square$ Female $\square$ Male

10. What is your age? (SELECT ONE)

$\square 21-30 \quad \square 51-60$

$\square 31-40 \quad \square 61-70$

$\square$ 41-50 $\square$ Older than 70

11. How many years have you been in practice? (SELECT ONE)

$\square 0-5$ years $\square 21-30$ years

$\square$ 6-10 years $\square>30$ years

$\square 11-20$ years in the tendency to refer patients with epilepsy when comparing family physicians unfamiliar with the risks associated with epilepsy surgery to those with a greater knowledge of said risks.

\section{INTERPRETATION}

Despite the estimated tens of thousands of patients who may benefit from epilepsy surgery, ${ }^{8}$ only $\sim 150$ epilepsy surgeries are performed each year in Ontario. ${ }^{7}$ The present study was designed to investigate knowledge of epilepsy and epilepsy surgery, as well as referral practices of family physicians in Ontario, given the possibility that too few patients are referred to neurologists or epileptologists.

\section{Sample Representativeness}

The validity of our results hinges on sample representativeness. The 2010 National Physician Survey ${ }^{9}$ serves as a practical point of comparison. The demographic data yielded by the present survey are depicted in Table 2 . The proportion of male respondents, age range, practice setting (urban vs. rural) and data pertaining to years in practice from the 2010 National Physician Survey $^{9}$ are similar to equivalent data from our present survey.

\section{Referral Practices}

Answers to questions 2 and 3 (see Table 3) address referral practices. Just over $80 \%$ of respondents "always" refer patients with epilepsy, presumably upon diagnosis. The International League Against Epilepsy (ILAE) uses the term "refractory" for cases where seizure freedom fails to be achieved despite adequate trials of two tolerated and appropriately selected AEDs. ${ }^{10}$ Survey results showed that $11.9 \%$ refer an epilepsy patient after a single medication has failed, and $3.0 \%$ do so after two medications have failed. It is unclear whether or not these practices reflect an approximation of the consensus view regarding management of refractory epilepsy. Of those family physicians who refer their epilepsy patients, the majority refer to general neurologists $(89.1 \%)$, while equalsized minorities (3.5\%) refer to epileptologists or internists. Overall, the results support the notion that family physicians by and large refer most patients with epilepsy to appropriate specialists, regardless of practice setting (urban vs. rural). While family physicians in practice for more than 20 years are less likely to refer $(75 \%)$ than those in practice for 20 years or less $(89 \%)$, again, the majority of family physicians appropriately refer patients with epilepsy.

\section{General Knowledge of Epilepsy and Epilepsy Surgery}

Family physicians' general knowledge of epilepsy and epilepsy surgery may help explain why epilepsy surgery services are underutilized. Questions 4 through 7 of the survey (see Table 4) were designed to assess such knowledge.

The best available evidence suggests that epilepsy surgery ought to be considered in a select number of cases of refractory epilepsy. ${ }^{1,11-14}$ Question 4 of the survey, which asks when surgical treatment ought to be considered, revealed that $53.7 \%$ of respondents agree with this sentiment, while $27.9 \%$ are unsure. The survey results may indicate a degree of reluctance among family physicians to consider epilepsy surgery, as $3.5 \%$ reported that surgery should never be considered and $14.9 \%$ that surgery should be considered only as a last resort. Overall, these results suggest mixed views among family physicians regarding when epilepsy surgery merits consideration. Question 5 of the present 


\section{Table 2: Demographics}

\begin{tabular}{l|c|c}
\hline Community of practice & $\boldsymbol{n}$ & $\boldsymbol{\%}$ \\
\hline Urban $(>100,000)$ & 149 & $74.1 \%$ \\
\hline Rural $(<100,000)$ & 52 & $25.9 \%$ \\
\hline Gender & 94 & $46.8 \%$ \\
\hline Male & 106 & $52.7 \%$ \\
\hline Female & \multicolumn{2}{|c}{} \\
\hline Age range & 5 & $2.5 \%$ \\
\hline $21-30$ & 40 & $19.9 \%$ \\
\hline $31-40$ & $\mathbf{6 1}$ & $\mathbf{3 0 . 3 \%}$ \\
\hline $41-50$ & 57 & $28.4 \%$ \\
\hline $51-60$ & 34 & $16.9 \%$ \\
\hline $61-70$ & 3 & $1.5 \%$ \\
\hline$>70$ & \multicolumn{2}{|}{} \\
\hline Years in practice & 29 & $14.4 \%$ \\
\hline $0-5$ & 17 & $8.5 \%$ \\
\hline $6-10$ & 51 & $25.4 \%$ \\
\hline $11-20$ & $\mathbf{5 7}$ & $\mathbf{2 8 . 4 \%}$ \\
\hline $21-30$ & 46 & $22.9 \%$ \\
\hline$>30$ & \multicolumn{2}{|c}{}
\end{tabular}

survey was meant to assess the knowledge of what types of epilepsy are amenable to surgery, the answers to which may imply a lack of knowledge in this area. Just over half of respondents $(53.2 \%)$ reported not knowing which types of epilepsy can be surgically treated.

Question 6 of the present survey addressed respondents' knowledge of the surgical risks involved. The largest percentage of responses (43.8\%) indicated "I don't know". Despite prevailing evidence of a low risk, ${ }^{6,7}$ only $8.5 \%$ of respondents felt that epilepsy surgery carries a low risk, and nearly $50 \%$ felt that surgery constituted a moderate to very high risk. It is possible that this may reflect a general impression of the risk of craniotomy

\section{Table 3: Referral Practices}

\begin{tabular}{l|c|c}
\hline Question (no. from Table 1) & $n$ & \% \\
\hline (Q2) When do you refer patient with epilepsy?* & $\mathbf{1 6 2}$ & $\mathbf{8 0 . 6 \%}$ \\
\hline Always & 24 & $11.9 \%$ \\
\hline After one medication has failed & 6 & $3 \%$ \\
\hline After two or more medications have failed & 7 & $3.5 \%$ \\
\hline Never (SKIP TO Q4) & $\mathbf{1 7 9}$ & $\mathbf{8 9 . 1 \%}$ \\
\hline (Q3) Where do you most commonly refer patients with epilepsy? & 7 & $3.5 \%$ \\
\hline General neurologist & 7 & $3.5 \%$ \\
\hline Epileptologist/epilepsy specialist & 1 & $0.5 \%$ \\
\hline Internal medicine specialist & 7 & $3.5 \%$ \\
\hline Other & & \\
\hline Never & \multicolumn{2}{|c}{} \\
\hline
\end{tabular}

${ }^{*}$ Two missing Items. for a variety of neurosurgical conditions rather than a direct understanding of the risks of epilepsy surgery.

With only approximately 150 surgical cases annually in the province, it is very likely that most of the respondents had no or limited contact with postoperative epilepsy surgery patients and thus would have no experience with which to answer questions about surgical risk. A similar explanation may underlie respondents' answers regarding the benefit of epilepsy surgery. Nearly half $(45.3 \%)$ responded "I don't know" to question 7, regarding the benefits of epilepsy surgery, and less than a quarter $(22.9 \%)$ believe that there is a high degree of benefit. Interestingly, there was no difference in the tendency to refer patients when comparing family physicians who are unfamiliar with the risks of epilepsy surgery to those who have greater knowledge about the risks, suggesting that this knowledge does not affect referral practices.

While the survey results suggest little familiarity with the risks and benefits or surgery, it must be noted that this knowledge is probably outside the scope of most family physicians' practices and that the majority appropriately refer patients to neurologists for definitive management. Nonetheless, as family physicians often serve as the point of first contact and a source of patient education, an improvement in familiarity would be desirable.

\section{Educating Family Physicians Regarding Epilepsy and Epilepsy Surgery}

The results of the present survey suggest a degree of unfamiliarity with a number of key areas pertaining to refractory epilepsy and epilepsy surgery. The data may thus suggest a role for education, as has been previously argued, ${ }^{8}$ though the content of a proposed education campaign has not been determined, and questions must be raised about the effectiveness of education campaigns in general.

Ontario's family physicians and their epilepsy patients may benefit from two free online resources: Epilepsy Ontario ${ }^{15}$ and the Canadian Appropriateness Study of Epilepsy Surgery (CASES). ${ }^{16}$ The first website was designed as a comprehensive source of information about epilepsy, while the second was designed to help physicians determine whether or not their patients with focal epilepsy should be evaluated for surgery.

The effectiveness of online resources in improving referral rates likely depends on the enthusiasm with which such resources are embraced. According to the 2010 National Physician Survey, 21.3\% of Ontario's family physicians "never" use internet-based education. ${ }^{9}$ The majority of Ontario's family physicians $(56.7 \%)$ refer their patients to educational websites, suggesting an interest in using such resources to educate patients (about disease information in $89.5 \%$ of cases and treatment in $63.4 \%$ ), if not to inform their medical practice. $^{9}$

An alternative approach may be a provincial or national campaign to educate family physicians regarding refractory epilepsy and epilepsy surgery. The United Kingdom's Defeat Depression Campaign serves as a useful example of a national education campaign. Through leaflets and consensus statements, two-thirds of general practitioners were aware of the campaign, and $40 \%$ had definitely or possibly adjusted their medical practice as a result. ${ }^{17}$ 


\section{Table 4: General Knowledge About Epilepsy Surgery}

\begin{tabular}{|c|c|c|}
\hline Question (no. from Table 1) & $n$ & $\%$ \\
\hline \multicolumn{3}{|c|}{$\begin{array}{l}\text { (Q4) When do you think that surgery should be considered for the treatment of } \\
\text { epilepsy? }\end{array}$} \\
\hline Always & 0 & $0 \%$ \\
\hline Never & 7 & $3.5 \%$ \\
\hline In selected cases & 108 & $\mathbf{5 3 . 7 \%}$ \\
\hline Only as a last resort & 30 & $14.9 \%$ \\
\hline I don't know & 56 & $27.9 \%$ \\
\hline \multicolumn{3}{|c|}{ (Q5) What type of epilepsy do you think can be surgically treated? } \\
\hline Generalized epilepsy & 5 & $2.5 \%$ \\
\hline Partial or focal epilepsy & 55 & $27.4 \%$ \\
\hline Neither & 4 & $2 \%$ \\
\hline Both & 30 & $14.9 \%$ \\
\hline I don't know & 107 & $53.2 \%$ \\
\hline \multicolumn{3}{|c|}{ (Q6) What is your impression of the risk of epilepsy surgery? } \\
\hline Low & 17 & $8.5 \%$ \\
\hline Moderate & 53 & $26.4 \%$ \\
\hline High & 32 & $15.9 \%$ \\
\hline Very high & 11 & $5.5 \%$ \\
\hline I don't know & 88 & $43.8 \%$ \\
\hline \multicolumn{3}{|c|}{ (Q7) What is your impression of the potential benefit of epilepsy surgery?* } \\
\hline Low & 9 & $4.5 \%$ \\
\hline Moderate & 50 & $24.9 \%$ \\
\hline High & 26 & $22.9 \%$ \\
\hline Very high & 4 & $2 \%$ \\
\hline I don't know & 91 & $45.3 \%$ \\
\hline
\end{tabular}

*Missing item.

\section{Other Factors Underlying Low Referral Rates of Epilepsy Patients}

While the results of the present survey suggest some unfamiliarity with certain areas of epilepsy and epilepsy surgery, it is unclear if this affects referral practices or low rates of epilepsy surgery in Ontario, as the majority of family physicians in fact do refer to neurologists. Thus, swift conclusions cannot be drawn about the value of providing further education to family physicians. Educational resources such as Epilepsy Ontario and CASES may be more useful for educating and empowering patients.

Access to epileptologists may be a more significant factor underlying the low rates of epilepsy surgery. Given that $80.6 \%$ of respondents always refer their epilepsy patients, it may be the case that neurologists are in turn referring too few of their epilepsy patients to epileptologists or epilepsy surgeons. ${ }^{18}$ Arguably, the burden of referral to epilepsy specialists ought to be shouldered by neurologists. This possibility in combination with limited access to epileptologists and epilepsy surgeons may partly explain Ontario's estimated low rate of epilepsy surgery. ${ }^{18}$ Among surveyed family physicians, $18.7 \%$ reported having "excellent" access to surgical specialists, $32.3 \%$ reported "very good" access, $29.9 \%$ reported "good" access, $15.4 \%$ reported "fair" access and
$3.7 \%$ reported poor access. ${ }^{9}$ Additionally, surgeons' varying access to operating room time and resources may compound the issue of access to services.

Limited access to advanced diagnostic services, such as epilepsy monitoring units with video EEG capabilities, may also to some degree explain the low rates of epilepsy surgery. The results from the 2010 National Physician Survey indicate that more that two-thirds of family physicians $(66.3 \%$ ) have access to advanced diagnostic services that ranges from "poor" to "good", in contrast to the roughly one-fifth $(21.5 \%)$ whose access ranges from "very good" to "excellent". ${ }^{9}$ While it is unclear if epilepsy monitoring units, EEG and video EEG fall under the rubric of advanced diagnostic services, the possibility remains that low rates of epilepsy surgery reflect deficiencies in the delivery of such services.

It must be acknowledged that, even if referrals to epileptologists and epilepsy surgeons occur at an appropriate frequency, a shortfall in these specialists may result in a low number of epilepsy surgeries for suitable patients despite the efforts of family physicians or other referring physicians.

Attitudes toward epilepsy surgery may be shaped in a broad sense by several factors, including the overall perception of epilepsy surgery as the standard of care as opposed to an experimental treatment. Indeed, the rapidly emerging consensus view among epileptologists and epilepsy surgeons is that referral to an epilepsy surgeon is warranted if there is no improvement in seizure control after two adequate trials of AEDs, as noted by Ontario's Epilepsy Implementation Task Force. ${ }^{19}$ Nevertheless, it may be that this view has not yet permeated all levels of the healthcare system, thus limiting enthusiasm for surgery among some healthcare providers and patients.

\section{STUdY Limitations}

While the survey's design is straightforward, it was not validated a priori, and thus the validity of its results may be challenged. However, as the survey was designed to measure relatively simple variables - namely, demographic data, referral practices, and basic knowledge of epilepsy and epilepsy surgery - the issue of validation may not affect the survey's results or interpretation. The response rate of $\sim 50 \%$ may also affect the generalizability of the survey's results. However, this response rate is more than double that of the 2010 National Physician Survey. ${ }^{9}$ With a relatively small sample size of 201 family physicians, it may be the case that the respondents' patients with epilepsy differ from those in other family physicians' practices. An extra survey question to obtain the average annual number of patients with epilepsy in each physician's practice may have provided some useful additional information regarding their patient rosters.

Also, it is unclear from the present survey data whether referral practices are directly linked to knowledge of epilepsy and epilepsy surgery. It may be that certain family physicians refer all patients with epilepsy for general management, as opposed to referring only those with intractable epilepsy. Future studies providing stratified analyses may differentiate referral practices between subgroups of family physicians.

\section{Conclusions}

The results of the present survey suggest a degree of unfamiliarity in the areas of epilepsy and epilepsy surgery. 
However, it is unclear that this accounts for the estimated small number of epilepsy surgeries performed in Ontario each year, as the majority of family physicians appropriately refer their patients with epilepsy to neurologists. Existing online resources may assist family physicians in identifying those who may be candidates for surgery and also help to empower patients. However, questions remain in terms of how effective these resources may be over the long term. Other factors such as referral practices of general neurologists, as well as access to epilepsy specialists, diagnostic services and operating room resources, may all explain the estimated small number of epilepsy surgeries performed in Ontario each year.

\section{SOURCES OF SUPPORT}

The Department of Clinical Neurological Sciences, Western University; The Ontario Brain Institute; the EpLink Program; and UCB Canada.

\section{Disclosures}

Jorge Burneo has received financial support for research from UCB Canada and Eisai Canada. He has been a speaker for UCB Canada and Eisai Canada, and has also been on the advisory board for Sunovion. David Steven does not have anything to disclose. Nicholas Cothros also has nothing to disclose.

\section{REFERENCES}

1. Fauser S, Zentner J. Critical review of palliative surgical techniques for intractable epilepsy. Adv Tech Stand Neurosurg. 2012; 39:165-94.

2. Thom M, Mathern GW, Cross JH, Bertram EH. Mesial temporal lobe epilepsy: how do we improve surgical outcome? Ann Neurol. 2010;68(4):424-34.

3. Wiebe S, Blume WT, Girvin JP, Eliasziw M, et al. Effectiveness and efficiency of surgery for temporal lobe epilepsy. N Engl J Med. 2001;345(5):311-8.

4. Engel J Jr, McDermott MP, Wiebe S, Langfitt JT, Stern JM, Dewar S, et al. Early surgical therapy for drug-resistant temporal lobe epilepsy: a randomized trial. JAMA. 2012;307 (9):922-30.
5. Perry MS, Duchowny M. Surgical versus medical treatment for refractory epilepsy: outcomes beyond seizure control. Epilepsia. 2013;54(12):2060-70.

6. Georgiadis I, Kapsalaki EZ, Fountas KN. Temporal lobe resective surgery for medically intractable epilepsy: a review of complications and side effects. Epilepsy Res Treat. 2013;752195. Epub ahead of print Oct 31.

7. Health Quality Ontario. Epilepsy surgery: an evidence summary. Ont Health Technol Assess Ser. 2012;12(17):1-28. Available at: http://www.ncbi.nlm.nih.gov/pmc/articles/PMC3428719/.

8. McLachlan RS. Commentary on epilepsy surgery in Canada. Can J Neurol Sci. 2001;28(1):4-5.

9. National Physician Survey. 2010 National Physician Survey. Available at: http://nationalphysiciansurvey.ca/surveys/2010survey/.

10. Kwan P, Arzimanoglou A, Berg AT, Brodie MJ, Allen Hauser W, Mathern G, et al. Definition of drug resistant epilepsy: consensus proposal by the ad hoc Task Force of the ILAE Commission on Therapeutic Strategies. Epilepsia. 2010;51(6):1069-77. Epub ahead of print Nov 3, 2009.

11. Miller JW, Hakimian S. Surgical treatment of epilepsy. Continuum (Minneap Minn). 2013;19(3 Epilepsy):730-42.

12. Jobst BC. Treatment algorithms in refractory partial epilepsy. Epilepsia. 2009;50(Suppl 8):51-6.

13. Englot DJ, Wang DD, Rolston JD, Shih TT, Chang EF. Rates and predictors of long-term seizure freedom after frontal lobe epilepsy surgery: a systematic review and meta-analysis. J Neurosurg. 2012;116(5):1042-8. Epub ahead of print Feb 3.

14. Ryvlin P. Beyond pharmacotherapy: surgical management. Epilepsia. 2003;44(Suppl 5):23-8.

15. Epilepsy Ontario. Available at: http://epilepsyontario.org/.

16. Appropriateness Tool for Epilepsy Surgery Evaluation. Available at: http://epilepsycases.com/default.aspx.

17. Rix S, Paykel ES, Lelliott P, Tylee A, Freeling P, Gask L, et al. Impact of a national campaign on GP education: an evaluation of the Defeat Depression Campaign. Br J Gen Pract. 1999; 49(439):99-102.

18. Roberts JI, Hrazdil C, Wiebe S, Sauro K, Vautour M, Wiebe N, et al. Neurologists' knowledge of and attitudes toward epilepsy surgery: a national survey. Neurology. 2015;84:159-66. Epub ahead of print Dec 10, 2014.

19. Critical Care Services Ontario. Provincial Guidelines for the Management of Epilepsy in Adults and Children. Available at: http:// www.braininstitute.ca/sites/default/files/provincial_guidelines_for_ the_management_of_epilepsy_is_adults_and_children_janurary_ 2015.pdf. 